\title{
Shaping Magnetite with Poly-L-arginine and pH: From Small Single Crystals to Large Mesocrystals
}

\author{
Lucas Kuhrts, ${ }^{\dagger}$ Elena Macías-Sánchez, ${ }^{\dagger}$ Nadezda V. Tarakina, ${ }^{\dagger}$ (i) Ann M. Hirt, ${ }^{\ddagger}$

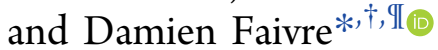 \\ ${ }^{\dagger}$ Max Planck Institute of Colloids and Interfaces, Am Mühlenberg 1, 14476 Potsdam, Germany \\ ${ }^{\ddagger}$ Department of Earth Science, ETH Zürich, Sonneggstrasse 5, 8092 Zürich, Switzerland \\ ${ }^{I}$ Aix-Marseille University, CNRS, CEA, BIAM, 13108 Saint-Paul-lez-Durance, France
}

Supporting Information

\begin{abstract}
Control over particle size, size distribution, and colloidal stability are central aims in producing functional nanomaterials. Recently, biomimetic approaches have been successfully used to enhance control over properties in the synthesis of those materials. Magnetotactic bacteria produce protein-stabilized magnetite away from its thermodynamic equilibrium structure. Mimicking the bacteria's proteins using poly-Larginine we show that by simply increasing the $\mathrm{pH}$, the dimensions of magnetite increase and a single- to mesocrystal transformation is induced. Using synchrotron X-ray diffraction and transmission electron microscopy, we show that magnetite nanoparticles with narrow size distributions and average diameters of $10 \pm 2 \mathrm{~nm}$ for $\mathrm{pH} 9,20 \pm 2 \mathrm{~nm}$ for $\mathrm{pH} \mathrm{10}$, and up to $40 \pm 4 \mathrm{~nm}$ for $\mathrm{pH} 11$ can be synthesized. We thus selectively produce superparamagnetic and stable single-domain particles merely by controlling the $\mathrm{pH}$. Remarkably, while an increase in $\mathrm{pH}$ brings about a thermodynamically driven decrease in size for magnetite without additives, this dependency on $\mathrm{pH}$ is inverted when poly-L-arginine is present.
\end{abstract}

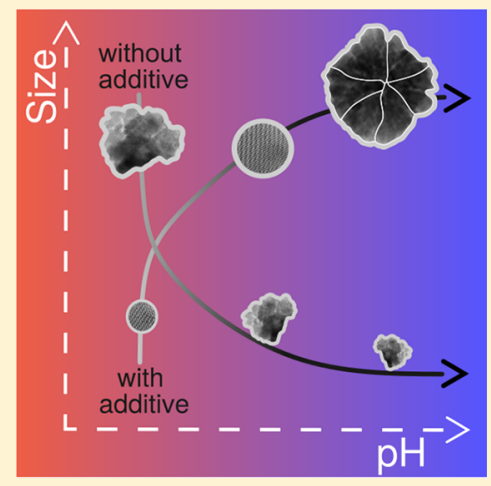

$\mathrm{P}$ roperties of materials typically change when confined to nanoscopic dimensions, opening the door to tailoring nanomaterials toward desired applications. Nanoparticles made from ferrimagnetic magnetite $\left(\mathrm{Fe}_{3} \mathrm{O}_{4}\right)$ exhibit superparamagnetic (SP), stable single-domain (SSD), or multidomain behavior depending on their size. ${ }^{1,2}$ SP nanoparticles are found below a size threshold of 20-30 nm and are widely employed in applications ranging from magnetic ink, data recording, drug delivery, magnetic resonance therapy (MRI), to hyperthermal cancer treatment. ${ }^{3,4}$ Above the SP size threshold and below $80-100 \mathrm{~nm}, 5$ magnetite nanoparticles show SSD character with an intrinsic remanent magnetization that is advantageous for certain biomedical and bioengineering applications. ${ }^{6}$ Controlling the size, and especially size distribution, of magnetite nanoparticles is thus essential to fine-tune their properties toward the desired application. ${ }^{7-10}$

For most applications, it is not only size that matters, but also colloidal stability, which prevents aggregation, and sedimentation is of equal importance. ${ }^{1,12}$ Colloidal suspension stability results when attractive and repulsive forces are in equilibrium. Attractive dipolar forces, which cause aggregation, especially in SSD magnetic nanoparticles, seriously compromise the usefulness of these nanoparticles in applications, such as medical ones where aggregation and sedimentation could clog blood vessels. Thus, to make these particles more operational, a continuous steric or electrostatic stabilization during the growth of these nanoparticles is necessary to counteract attractive magnetic forces, preventing aggregation.
Synthesizing SSD magnetite nanoparticle under mild conditions by co-precipitation of ferrous and ferric iron has so far been a challenge as particle sizes typically range between 2 and $12 \mathrm{~nm}$ with a rather broad size distribution when prepared at different $\mathrm{pHs}$ and ionic strengths, failing in addition to being colloidally stable. ${ }^{13,14}$ We recently showed that magnetite particles can be grown beyond the SSD sizes at mild temperatures ${ }^{15}$ and/or by increasing the reaction times, ${ }^{16}$ but they still form colloidally unstable precipitates.

One encouraging way to overcome these challenges has been adopting biomimetic approaches. ${ }^{17}$ Baumgartner et al. emulated the proteome architecture of magnetotactic bacteria and used the polyamino acid poly-L-arginine (polyR) in the in vitro precipitation of magnetite, which resulted in colloidally stable, mesocrystalline nanoparticles of $\sim 40 \mathrm{~nm}$ diameter. The magnetic behavior of the mesocrystals surprisingly reflected that of the superstructure ${ }^{18}$ rather than that of the building blocks, as reported earlier. ${ }^{19}$

Encouraged by these results, we engaged in further developments of these biomimetic functional materials controlling the size and the inherent magnetic properties while exploring polyR properties to alter magnetite's nucleation and growth characteristics. Here we report the co-

Received: June 19, 2019

Accepted: August 5, 2019

Published: August 13, 2019 
precipitation of ferrous and ferric iron in the presence of polyR at $\mathrm{pH}$ values between 9 and 11, resulting in colloidally stable magnetite nanoparticles with a tunable diameter between 10 and $40 \mathrm{~nm}$, showing a morphological transition from spherical single crystals to substructured mesocrystals for high $\mathrm{pH}$. This approach enabled us to selectively produce SP as well as SSD particles with an exceptionally narrow size distribution, as evidenced by (high-resolution) transmission electron microscopy (HR)TEM, synchrotron-based X-ray powder diffraction (XRPD), and vibrating sample magnetometry (VSM).

The polyR/magnetite nanoparticles were synthesized as in Baumgartner et al. ${ }^{20}$ Briefly, a computer-controlled titration device was connected to a $\mathrm{pH}$ electrode, and a dosing device added the iron solution into an alkaline solution of polyR. Particles were grown at $\mathrm{pH}$ values of 9, 10, and 11 for $2 \mathrm{~h}$ and analyzed using synchrotron $\mathrm{X}$-ray diffraction. The analysis showed an increase in particle size as the $\mathrm{pH}$ increased. The azimuthally integrated full XRPD diffractograms are shown in Figure 1, with the inset showing a magnified view of the (311)

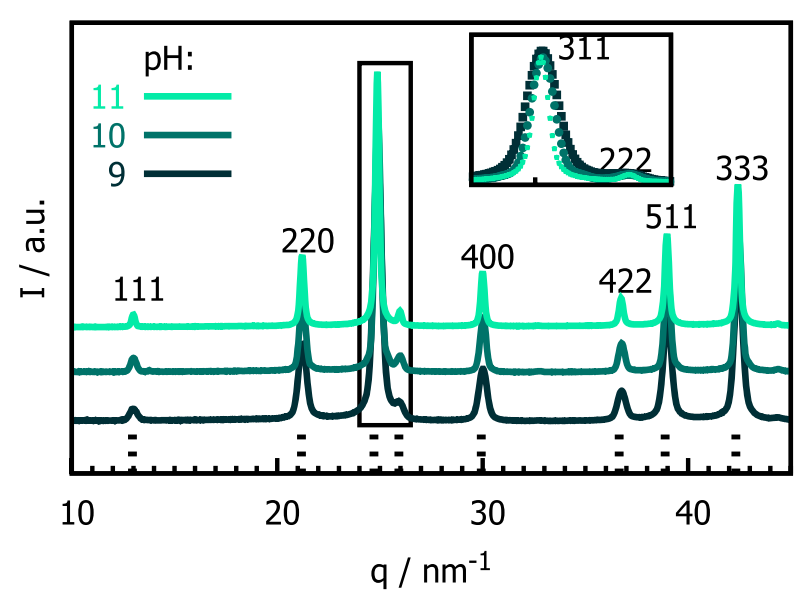

Figure 1. XRPD measurements of magnetite prepared at $\mathrm{pH} 9,10$, and 11 . The inset shows the magnified (311) reflection. The decrease in particle size with decreasing $\mathrm{pH}$ is evidenced by broadening of this reflection. Calculated magnetite reflections are indicated as dotted lines matching the measured diffraction pattern, which has been indexed accordingly. reflection. A broadening of this, and any other reflection, can be directly attributed to a decrease in grain size. This decrease is visible at lower-precipitation $\mathrm{pH}$. Using the Scherrer equation, ${ }^{21}$ we calculated nanoparticle sizes from the full width at half-maximum of the reflection, which shows particle diameters ranging from $10 \pm 0.5 \mathrm{~nm}$ for $\mathrm{pH} 9$ to $14 \pm 1 \mathrm{~nm}$ for $\mathrm{pH} 10$ and $24 \pm 2 \mathrm{~nm}$ for $\mathrm{pH} 11$. Standard deviations were calculated from the mean particle size of triplicates, showing a high reproducibility of the synthesis. Lattice constants for the cubic system $(a=b=c)$ were obtained from the (311) peak position and calculated to be $8.3734,8.3741$, and $8.3768 \AA$ for $\mathrm{pH} 9,10$, and 11 , respectively, indicating that the obtained particles are indeed magnetite that has undergone slight surface oxidation, ${ }^{22}$ resulting in a decrease of the lattice constant compared to compositionally pure magnetite $(8.3965$ $\AA$ ). The effect of surface oxidation decreases with increasing particle size, which is also observed for magnetite prepared without any additives. ${ }^{16}$

Complementary TEM measurements, seen in Figure 2, confirm the increase in particle size as the $\mathrm{pH}$ is increased. In determining individual sizes for at least 200 particles, we determined intrinsic particle size distributions of $10 \pm 2 \mathrm{~nm}$ for $\mathrm{pH} 9,20 \pm 1.8 \mathrm{~nm}$ for $\mathrm{pH} \mathrm{10}$, and $38 \pm 4.8 \mathrm{~nm}$ for $\mathrm{pH} 11$. For comparison, TEM micrographs of corresponding particles prepared in the absence of polyR are shown in the SI. Fast Fourier transformations (FFTs) of HRTEM images of single particles prepared in the presence of polyR were indexed according to an inverse spinel structure with crystal lattice spacing of magnetite. Note the discrepancies in particle size found in Table 1, which are determined by TEM or XRPD. As XRPD is only sensitive to an effective volume measured in the direction of the [311] vector along which the diffraction is coherent, results may differ from TEM, where the radius is calculated from a spatially averaged area projected from a three-dimensional structure. Further, thresholding for size determination in TEM may exclude small particles, which in XRPD contribute to a significant peak broadening, lowering calculated mean sizes. Both methods, however, demonstrate an increase in particles size as the $\mathrm{pH}$ increases.

In addition to the observed change in particle size, a clear $\mathrm{pH}$-dependent change in morphology is visually evident: while
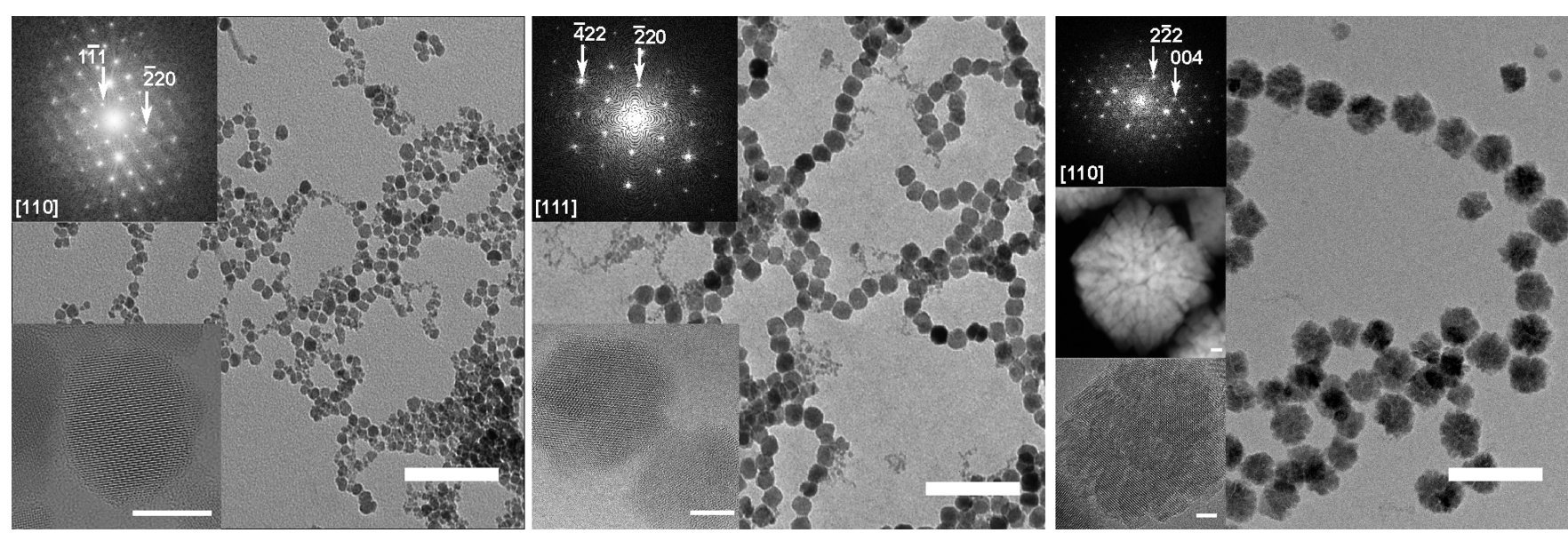

Figure 2. TEM micrographs of nanoparticles prepared at $\mathrm{pH} 9,10$, and 11 (from left to right, scale bar $100 \mathrm{~nm}$ ). The insets show HRTEM images (scale bar $5 \mathrm{~nm}$ ) of single nanoparticles (bottom). In the second (top) inset, the FFT of the HRTEM image of the particles is shown, which could be indexed according to the inverse spinel magnetite structure. The HAADF STEM micrograph in the center inset of (c) highlights well the mesocrystalline, substructured morphology of particles prepared at $\mathrm{pH} 11$. 
Table 1. Mean Particle Sizes at Different pHs Analyzed by TEM and XRPD ${ }^{a}$

$\begin{array}{rcccc}\mathrm{pH} & D_{\text {XRPD }}[\mathrm{nm}] & D_{\mathrm{TEM}}[\mathrm{nm}] & H_{\mathrm{C}}[\mathrm{mT}] & a[\AA] \\ 9 & 10 \pm 0.5 & 10 \pm 2 & 0 & 8.3734(1) \\ 10 & 14 \pm 1.7 & 20 \pm 2 & 6 & 8.3740(6) \\ 11 & 24 \pm 2.0 & 38 \pm 5 & 12 & 8.3767(8)\end{array}$

${ }^{a}$ Particle size distributions from TEM were calculated from single particle size in an ensemble of at least 200 particles, while for XRPD mean particle sizes were calculated from mean sizes of triplicates. VSM shows a change from SP to SSD behavior with the appearance of a coercive force $\left(H_{\mathrm{C}}\right)$ for particles prepared at $\mathrm{pH} 10$ and 11 . The lattice parameter $(a)$ increases with increasing $\mathrm{pH}$.

nanoparticles appear spherical at $\mathrm{pH} 9$ and 10, they form flower-like substructured mesocrystals at $\mathrm{pH} 11$. This substructured morphology is even more visible in the HAADF STEM image shown in the middle inset of Figure $2 \mathrm{c}$. The morphology, size, and size distribution of the particles, as seen in the TEM images, are found to remain unaltered in storage up to 7 days, when kept in solution under anoxic conditions (see Figure 2 in the SI). Colloidal stability could also be visually confirmed for more than 3 months (see the SI). To determine the magnetic properties of the nanoparticles, we performed magnetic hysteresis measurements on a VSM device on bulk samples at room temperature (Figure 3). As the

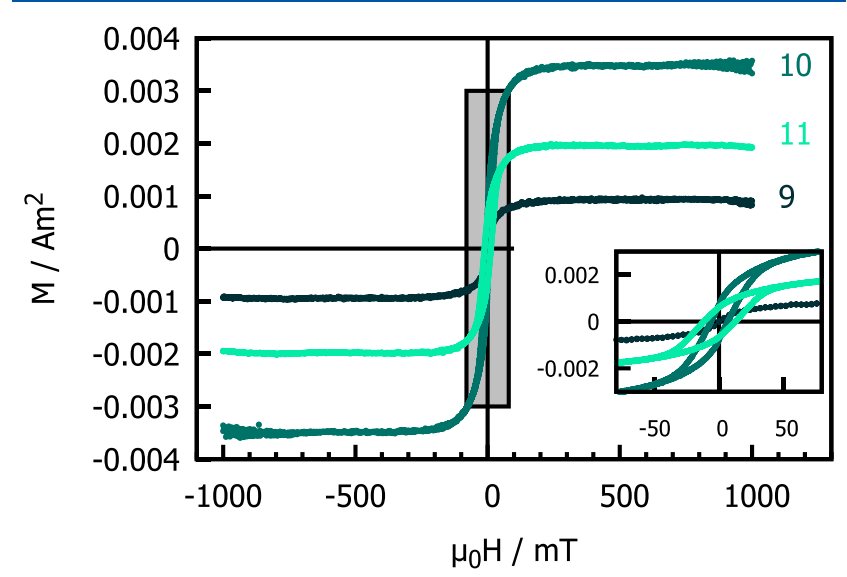

Figure 3. Magnetic hysteresis loops of particles prepared at different pHs. The gray region is shown in higher magnification in the inset to show the opening of the hysteresis loop for particles prepared at $\mathrm{pH}$ 10 and 11. Particles prepared at $\mathrm{pH} 9$ show no opening of the loop and thus have no coercivity at the given temperature typical for SP particles. Coercivities of 6 and $12 \mathrm{mT}$ for particles prepared at $\mathrm{pH} 10$ and 11 were determined from the field strength to completely demagnetize the particles after full magnetization.

maximum magnetization could not be normalized to the mass of the sample, we focus only on the coercivity $\left(H_{\mathrm{C}}\right)$ to discriminate between SP and SSD particles. While SP particles show no hysteresis $\left(H_{\mathrm{C}}=0\right)$, SSD particles are characterized by an open hysteresis loop $\left(H_{\mathrm{C}}>0\right)$ when a reversed magnetic field is applied. A change from SP to SSD behavior can be seen between $\mathrm{pH} 9$ and 10, illustrated in the inset of Figure 3, in the opening of the hysteresis loop. Moreover, the increase in coercivity from 6 to $12 \mathrm{mT}$ for particles prepared at $\mathrm{pH} 10$ and 11 , respectively, is congruent with a growth of the domain size of the SSD particles, ${ }^{23}$ which is also consistent with structural results from TEM and XRPD. The substructured morphology of particles of $\mathrm{pH} 11$ yields a larger particle whose crystallographic orientation is constant throughout the structure. The magnetic properties, therefore, are very similar to those that have been reported for synthesized magnetite or magnetosomes of magnetotactic bacteria with a similar size of $34 \mathrm{~nm}^{24}$ as well as for other mesocrystals. ${ }^{25}$ This attests that the mesocrystal structure behaves as would be expected for a similarly sized single particle.

The arrest of particle sizes and morphologies, as obtained from TEM measurements of freshly synthesized and 7 days aged samples (see Figure 1 in the SI), may suggest that the system is at thermodynamic equilibrium. However, polymer induced electrostatic and steric repulsion, which inhibits coagulation of nanoparticles, as well as the ultralow solubility of iron at strongly alkaline conditions, preventing Ostwald ripening, are considerable energetic barriers that may kinetically trap the nanoparticles in a thermodynamically unfavorable state. Still, this stabilization-preventing coagulation and molecular ripening processes-are most favorable for prospective applications, especially for SSD particles, which normally aggregate and precipitate due to magnetic interaction.

While we find an increase in particle size as the $\mathrm{pH}$ increases, magnetite nanoparticles in the absence of additives formed by co-precipitation in alkaline solution decrease in size with increasing alkalinity. We use particle sizes of magnetite prepared under the same conditions but without polyR, as described in the literature, ${ }^{26}$ and compared them to $\mathrm{pH}$ dependent particle sizes obtained in the presence of polyR (Figure 4). An inversion of the $\mathrm{pH}$ dependence of the

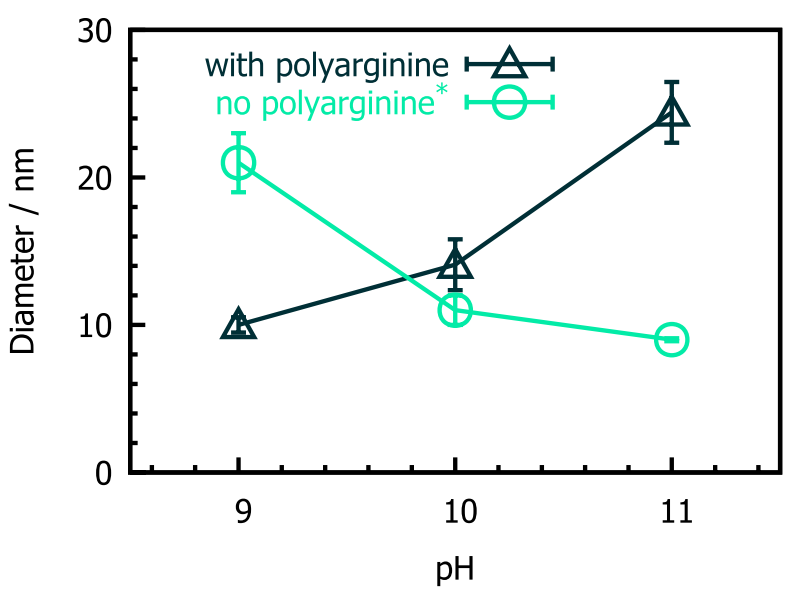

Figure 4. Particle sizes calculated using the Scherrer equation from the (311) magnetite reflection at $\sim 25 \mathrm{~nm}^{-1}$ of particles prepared in the presence of polyR compared to literature values $*$ of magnetite prepared with the same protocol without additives. ${ }^{26}$ Error bars were calculated from the mean size of triplicates.

nanoparticle size is evident. The decrease in particle size with increasing $\mathrm{pH}$ for bare particles was modeled on the basis of classical nucleation theory, following a semiquantitive approach by Jolivet et al. ${ }^{27}$ They proposed that an increase in surface charge density caused by a stronger deprotonation at high $\mathrm{pH}$ is directly related to a decrease in oxide/water surface tension, thereby decreasing particle size to minimize the system's free energy. Using this model and potentiometric determination $^{14}$ of the surface charge density of freshly prepared magnetite nanoparticles makes it possible to predict magnetite particle sizes as a function of $\mathrm{pH}$. Further, the degree of condensation of counterions at the charged magnetite/water 
interface has a significant influence on the sizes of magnetic nanoparticles in solution. ${ }^{28}$ An increasing counterion concentration will decrease the interfacial tension because of stronger adsorption, as predicted by the Gibbs adsorption isotherm, and will thus lead to a decrease in particle size. Vayssieres et al. ${ }^{28}$ demonstrated that the diameter of magnetite nanoparticles varies, from between $4 \mathrm{~nm}$ at low $\mathrm{NaNO}_{3}$ concentrations at a given $\mathrm{pH}$ to $0.8 \mathrm{~nm}$ for high concentrations. As for ions, we may infer that adsorption of polyR at the magnetite/water interface induces a lower surface tension that would lead to a decrease in particle size. We expect this effect to be even more pronounced in our case as the adsorption of a polyelectrolyte with $n$ charges will come along with a smaller entropic penalty compared to the adsorption of $n$ monovalent counterions, as predicted purely based on statistical placement of the $n$ charges. Unexpectedly, for the polyR magnetite hybrids, we observed the opposite effect as they increase in size with increasing $\mathrm{pH}$. This unusual $\mathrm{pH}$ effect rules out that the formation of magnetite in the presence of polyR can be easily explained by notions of classical nucleation based on thermodynamic energy minimization, where particles are thought to grow from stable nuclei by the accretion of ions, resulting in dense, homogeneous particles.

There are many examples of biological ${ }^{29}$ and synthetic ${ }^{30,31}$ systems following nonclassical nucleation pathways. These systems often exhibit an excess surface charge, where oppositely charged additives are thought to kinetically trap transient precursor phases, altering the crystallization pathway and resulting in a wealth of sophisticated structures and morphologies of nanoparticles. For magnetotactic bacteria, it was possible to identify transient ferric hydroxide phases stabilized by charged proteins that crystallize to form magnetite via nanometric (oxyhydr)oxide intermediates. ${ }^{16}$ Polymorph selection in precipitation of $\mathrm{CaCO}_{3}$ forming either vaterite or amorphous calcium carbonate in the presence of polyaspartic acid has been demonstrated in in vitro experiments. ${ }^{31}$ Moreover, prior research has already demonstrated that adding negatively charged polysaccharides inhibits magnetite nucleation at $\mathrm{pH}$ values up to $13 .{ }^{30}$

The unifying concept of the given examples, of both natural and synthetic origin, is the existence of thermodynamically less stable polymorphs such as iron oxyhyroxide or amorphous calcium carbonate from which the thermodynamically more stable phases magnetite and calcite are formed. ${ }^{32}$ Past research has shown that interaction with charged macromolecules results in kinetic stabilization, preventing crystallization into the thermodynamically more stable (and also more dense) phase. Proving (or disproving) the existence of these structures will thus be the next logical step toward understanding the influence of polyR on the crystallization of magnetite.

In conclusion, we show that SP as well as SSD magnetite nanoparticles can be selectively grown in the presence of polyR simply by changing the $\mathrm{pH}$ of the precipitation solution. Even though the effect of $\mathrm{pH}^{33,34}$ and of biological ${ }^{35,36}$ and synthetic $^{37}$ additives on the precipitation of magnetite has been extensively studied within recent years, we believe that the presented control over size and size distribution of the nanoparticles is exceptional. We thus combine many of the previously reported advantages in one system. These properties in combination with their long-term colloidal stability render these biomimetic functional materials ideal for applications. Unexpectedly, the size of the nanoparticles increases with increasing $\mathrm{pH}$, in contrast to naked magnetite particles produced under the same conditions, which decrease in particle size when the precipitation $\mathrm{pH}$ is increased.

Classical notions of nucleation fail to explain this unexpected $\mathrm{pH}$ dependence as well as the complex, substructured morphology of the mesocrystals formed at $\mathrm{pH} 11$. Thus, reference to nonclassical nucleation theories suggests that the magnetite/polyR nanoparticles may crystallize from polymerstabilized transient, low-density iron phases. These noncrystalline iron phases then crystallize only when they attach to the growing nanoparticle's surface, adopting the nanoparticle's crystallography. This mechanism may explain the singlecrystalline behavior of our substructured particles. Magnetite formation via these transient iron phases was already considered by others, a polymer induced stabilization of them, however, has so far not been reported. ${ }^{38,39}$ If this mechanism will be proved, we may have found a way to alter the nucleation pathway of magnetite that, in the presence of poly-arginine, would not follow a pathway of thermodynamic energy minimization, consistent with magnetite biomineralization in the presence of charged proteins. Further measurements will provide necessary data for an extensive understanding of the formation pathway of the polyR/magnetite particles, an understanding that promises to deepen our knowledge of crystal morphology control by charged macromolecules in natural as well as synthetic systems.

\section{ASSOCIATED CONTENT}

\section{S Supporting Information}

The Supporting Information is available free of charge on the ACS Publications website at DOI: 10.1021/acs.jpclett.9b01771.

Full description of the materials and methods, histograms of particle size distributions of fresh and aged nanoparticles, and photographs of solutions stored for 1 week and 3 months (PDF)

\section{AUTHOR INFORMATION}

\section{Corresponding Author}

*E-mail: damien.faivre@mpikg.mpg.de.

ORCID

Nadezda V. Tarakina: 0000-0002-2365-861X

Ann M. Hirt: 0000-0002-2193-0472

Damien Faivre: 0000-0001-6191-3389

\section{Notes}

The authors declare no competing financial interest.

\section{ACKNOWLEDGMENTS}

This project was supported by the Max Planck Society and the DFG within the ERA-Chemistry Framework (Project Number FA 835/12-1). The authors thank Charlet Wenig for her artistic support in the preparation of the graphical abstract and Jens Baumgartner for helpful insights into nucleation theories of magnetite and Tobias Heil for his support on the TEM and for supplying the STEM image of the mesocrystal. For the revision and proofreading of the manuscript we thank Daniel Chevrier and Marc Abernathy.

\section{REFERENCES}

(1) Schwertmann, U.; Cornell, R. The Iron Oxides; Wiley-VCH, 2004. 
(2) Sherwood, G. D.; Dunlop, J.; Özdemir, Ö. Rock Magnetism: Fundamentals and Frontiers. Mineralogical Magazine 2002, 66, 232232.

(3) Lang, C.; Schüler, D.; Faivre, D. Synthesis of magnetite nanoparticles for bio- and nanotechnology: Genetic engineering and biomimetics of bacterial magnetosomes. Macromol. Biosci. 2007, 7, 144-151.

(4) Lu, A. H.; Salabas, E. L.; Schüth, F. Magnetic nanoparticles: Synthesis, protection, functionalization, and application. Angew. Chem., Int. Ed. 2007, 46, 1222-1244.

(5) Muxworthy, A. R.; Williams, W. Critical single-domain/ multidomain grain sizes in noninteracting and interacting elongated magnetite particles: Implications for magnetosomes. Journal of Geophysical Research: Solid Earth 2006, 111, 3-9.

(6) Hirsch, R.; Katz, E.; Willner, I. Magneto-switchable bioelectrocatalysis [30]. J. Am. Chem. Soc. 2000, 122, 12053-12054.

(7) Laurent, S.; Forge, D.; Port, M.; Roch, A.; Robic, C.; Vander Elst, L.; Muller, R. N. Magnetic iron oxide nanoparticles: Synthesis, stabilization, vectorization, physicochemical characterizations and biological applications. Chem. Rev. 2008, 108, 2064-2110.

(8) Shin, T. H.; Choi, Y.; Kim, S.; Cheon, J. Recent advances in magnetic nanoparticle-based multi-modal imaging. Chem. Soc. Rev. 2015, 44, 4501-4516.

(9) Lak, A.; Kraken, M.; Ludwig, F.; Kornowski, A.; Eberbeck, D.; Sievers, S.; Litterst, F. J.; Weller, H.; Schilling, M. Size dependent structural and magnetic properties of $\mathrm{FeO}-\mathrm{Fe} 3 \mathrm{O} 4$ nanoparticles. Nanoscale 2013, 5, 12286-12295.

(10) Feld, A.; Weimer, A.; Kornowski, A.; Winckelmans, N.; Merkl, J. P.; Kloust, H.; Zierold, R.; Schmidtke, C.; Schotten, T.; Riedner, M.; Bals, S.; Weller, H. Chemistry of Shape-Controlled Iron Oxide Nanocrystal Formation. ACS Nano 2019, 13, 152-162.

(11) Gupta, A. K.; Gupta, M. Synthesis and surface engineering of iron oxide nanoparticles for biomedical applications. Biomaterials 2005, 26, 3995-4021.

(12) Champagne, P. O.; Westwick, H.; Bouthillier, A.; Sawan, M. Colloidal stability of superparamagnetic iron oxide nanoparticles in the central nervous system: A review. Nanomedicine 2018, 13, 13851400.

(13) Babes, L.; Denizot, B.; Tanguy, G.; Le Jeune, J. J.; Jallet, P. Synthesis of Iron Oxide Nanoparticles Used as MRI Contrast Agents: A Parametric Study. J. Colloid Interface Sci. 1999, 212, 474-482.

(14) Vayssières, L.; Chanéac, C.; Tronc, E.; Jolivet, J. P. Size tailoring of magnetite particles formed by aqueous precipitation: an example of thermodynamic stability of nanometric oxide particles. $J$. Colloid Interface Sci. 1998, 205, 205-212.

(15) Widdrat, M.; Schneck, E.; Reichel, V.; Baumgartner, J.; Bertinetti, L.; Habraken, W.; Bente, K.; Fratzl, P.; Faivre, D. Combined Experimental and Theoretical Approach to the Kinetics of Magnetite Crystal Growth from Primary Particles. J. Phys. Chem. Lett. 2017, 8, 1132-1136.

(16) Baumgartner, J.; Bertinetti, L.; Widdrat, M.; Hirt, A. M.; Faivre, D. Formation of Magnetite Nanoparticles at Low Temperature: From Superparamagnetic to Stable Single Domain Particles. PLoS One 2013, 8, e57070.

(17) Mirabello, G.; Lenders, J. J. M.; Sommerdijk, N. A. J. M.; Soc, C.; Mirabello, G.; Lenders, J. J. M.; Sommerdijk, N. A. J. M.; Soc, C. Bioinspired synthesis of magnetite nanoparticles. Chem. Soc. Rev. 2016, 45, 5085-5106.

(18) Reichhelm, A.; Haubold, D.; Eychmüller, A. Ligand Versatility in Supercrystal Formation. Adv. Funct. Mater. 2017, 27, 1700361.

(19) Ge, J.; Hu, Y.; Biasini, M.; Beyermann, W. P.; Yin, Y. Superparamagnetic magnetite colloidal nanocrystal clusters. Angew. Chem., Int. Ed. 2007, 46, 4342-4345.

(20) Baumgartner, J.; Antonietta Carillo, M.; Eckes, K. M.; Werner, P.; Faivre, D. Biomimetic magnetite formation: From biocombinatorial approaches to mineralization effects. Langmuir 2014, 30, 21292136.
(21) Langford, J. I.; Wilson, A. J. C. Scherrer after sixty years: A survey and some new results in the determination of crystallite size. J. Appl. Crystallogr. 1978, 11, 102-113.

(22) Fischer, A.; Schmitz, M.; Aichmayer, B.; Fratzl, P.; Faivre, D. Structural purity of magnetite nanoparticles in magnetotactic bacteria. J. R. Soc., Interface 2011, 8, 1011-1018.

(23) Kneller, E. F.; Luborsky, F. E. Particle size dependence of coercivity and remanence of single-domain particles. J. Appl. Phys. 1963, 34, 656-658.

(24) Kumari, M.; Widdrat, M.; Tompa, É.; Uebe, R.; Schüler, D.; Pósfai, M.; Faivre, D.; Hirt, A. M. Distinguishing magnetic particle size of iron oxide nanoparticles with first-order reversal curves. J. Appl. Phys. 2014, 116, 124304.

(25) Reichel, V.; Kovács, A.; Kumari, M.; Bereczk-tompa, É.; Schneck, E.; Diehle, P.; Pósfai, M.; Hirt, A. M.; Duchamp, M.; Duninborkowski, R. E.; Faivre, D. Single crystalline superstructured stable single domain magnetite nanoparticles. Sci. Rep. 2017, 7, 1-8.

(26) Baumgartner, J.; Dey, A.; Bomans, P. H. H.; Le Coadou, C.; Fratzl, P.; Sommerdijk, N. A. J. M.; Faivre, D. Nucleation and growth of magnetite from solution. Nat. Mater. 2013, 12, 310-314.

(27) Jolivet, J.-P.; Froidefond, C.; Pottier, A.; Chaneac, C.; Cassaignon, S.; Tronc, E.; Euzen, P. Size tailoring of oxide nanoparticles by precipitation in aqueous medium. A semiquantitative modelling. J. Mater. Chem. 2004, 14, 3281.

(28) Vayssieres, L. On the thermodynamic stability of metal oxide nanoparticles in aqueous solutions. Int. J. Nanotechnol. 2005, 2, 411.

(29) Albéric, M.; Bertinetti, L.; Zou, Z.; Fratzl, P.; Habraken, W.; Politi, Y. The Crystallization of Amorphous Calcium Carbonate is Kinetically Governed by Ion Impurities and Water. Advanced Science 2018, 5, 1701000 .

(30) Jones, F.; Cölfen, H.; Antonietti, M. Iron oxyhydroxide colloids stabilized with polysaccharides. Colloid Polym. Sci. 2000, 278, 491501.

(31) Zou, Z.; Bertinetti, L.; Politi, Y.; Fratzl, P.; Habraken, W. J. E. M. Control of Polymorph Selection in Amorphous Calcium Carbonate Crystallization by Poly(Aspartic Acid): Two Different Mechanisms. Small 2017, 13, 1603100.

(32) Zahn, D. Thermodynamics and Kinetics of Prenucleation Clusters, Classical and Non-Classical Nucleation. ChemPhysChem 2015, 16, 2069-2075.

(33) Gnanaprakash, G.; Mahadevan, S.; Jayakumar, T.; Kalyanasundaram, P.; Philip, J.; Raj, B. Effect of initial $\mathrm{pH}$ and temperature of iron salt solutions on formation of magnetite nanoparticles. Mater. Chem. Phys. 2007, 103, 168-175.

(34) Nishio, K.; Ikeda, M.; Gokon, N.; Tsubouchi, S.; Narimatsu, H.; Mochizuki, Y.; Sakamoto, S.; Sandhu, A.; Abe, M.; Handa, H. Preparation of size-controlled (30-100 nm) magnetite nanoparticles for biomedical applications. J. Magn. Magn. Mater. 2007, 310, 24082410.

(35) Arakaki, A.; Masuda, F.; Amemiya, Y.; Tanaka, T.; Matsunaga, T. Control of the morphology and size of magnetite particles with peptides mimicking the $\mathrm{Mms} 6$ protein from magnetotactic bacteria. J. Colloid Interface Sci. 2010, 343, 65-70.

(36) Rawlings, A. E.; Somner, L. A.; Fitzpatrick-Milton, M.; Roebuck, T. P.; Gwyn, C.; Liravi, P.; Seville, V.; Neal, T. J.; Mykhaylyk, O. O.; Baldwin, S. A.; Staniland, S. S. Artificial coiled coil biomineralisation protein for the synthesis of magnetic nanoparticles. Nat. Commun. 2019, 10, 1-9.

(37) Altan, C. L.; Gurten, B.; Sadza, R.; Yenigul, E.; Sommerdijk, N. A.; Bucak, S. Poly(acrylic acid)-directed synthesis of colloidally stable single domain magnetite nanoparticles via partial oxidation. J. Magn. Magn. Mater. 2016, 416, 366-372.

(38) Tronc, E.; Belleville, P.; Jolivet, J. P.; Livage, J. Transformation of Ferric Hydroxide into Spinel by FeII Adsorption. Langmuir 1992, 8, 313-319.

(39) Sun, S.; Gebauer, D.; Colfen, H. Alignment of Amorphous Iron Oxide Clusters: A Non-Classical Mechanism for Magnetite Formation. Angew. Chem., Int. Ed. 2017, 56, 4042-4046. 